\title{
P006: Highlights in bloodstream infections: where does the patient acquire the infection?
}

\author{
M Rodriguez-Aguirregabiria*, T Gimenez-Julvez, J Rodriguez-Aguirregabiria, M Villanova, P Rico Cepeda, \\ E Palencia Herrejon \\ From 2nd International Conference on Prevention and Infection Control (ICPIC 2013) \\ Geneva, Switzerland. 25-28 June 2013
}

\section{Introduction}

Bloodstream infections (BSI) still account for significant morbidity and mortality.

\section{Objectives}

The objective of this study was to describe the epidemiology, etiology, sources and adequacy of empiric antimicrobial treatment in BSI.

\section{Methods}

A retrospective study about all BSI diagnosed during one year. The pattern resistant pathogen study was EPINE-EPPS project.

\section{Results}

340 patients were included. Median age was 74.5 years [interquartile range (IQR), 58.5-80.5]; acute physiology and chronic health evaluation (APACHE II) score was 13 (IQR, 7-29).

BSI were community-acquired in $56 \%$ of the cases. The most common source of BSI was urinary tract (48.3\%), intra-abdominal $(25.6 \%)$ and lower respiratory tract infections (18.6\%). The most commonly isolated microorganisms were: Escherichia coli, K. pneumoniae, S.aureus (15\% oxacilin resistant) and S. pneumoniae. The $8.6 \%$ of enterobacteracea family produced extended-spectrum Blactamasas (ESBLs). Inappropriate treatment was observed in $24.5 \%$ and crude mortality rate was $7.7 \%$.

$28 \%$ BSI were nosocomial-acquired. The sources of BSI were unknown in $31.7 \%$ of the cases and catheterrelated in $25.7 \%$. The secondary sources of BSI were intra-abdominal in $57 \%$ of the cases. The most common isolated microorganisms were: S.epidermidis and other coagulasa negative, Candida, S. aureus (36\% oxacilin resistant) and E. coli. 25\% of enterobacteracea family were ESBLs. We found 5 BSI caused by Acitetobacter carbapenem (CPM) resistant and 2 BSI by $P$. aeruginosa CPM resistant. Inappropriate treatment was observed in $52.5 \%$ and mortality rate was $28.7 \%$.

Health-care related BSI produced $15.1 \%$ of the cases. The source of BSI were unknown in $22.6 \%$ and catheterrelated in $11.3 \%$. The secondary sources of BSI were urinary tract $(60 \%)$, intra-abdominal $(31.4 \%)$ and respiratory tract infections $(8.6 \%)$. The most common microorganisms were: E.coli, S.aureus (25\% oxacilin resistant), $S$. epidermidis and K.pneumoniae. Inappropriate treatment was noticed in $34 \%$ and mortality rate was $17 \%$.

\section{Conclusion}

The knowledge of local epidemiology is a capital information to improve empiric antimicrobial treatment and to reduce mortality-related inappropriate treatment.

\section{Disclosure of interest}

None declared.

Published: 20 June 2013

doi:10.1186/2047-2994-2-S1-P6

Cite this article as: Rodriguez-Aguirregabiria et al:: P006: Highlights in bloodstream infections: where does the patient acquire the infection? Antimicrobial Resistance and Infection Control 2013 2(Suppl 1):P6.

Hospital Universitario Infanta Leonor, Madrid, Spain

(c) 2013 Rodriguez-Aguirregabiria et al; licensee BioMed Central Ltd. This is an Open Access article distributed under the terms of the B.TMed Central Creative Commons Attribution License (http://creativecommons.org/licenses/by/2.0), which permits unrestricted use, distribution, and reproduction in any medium, provided the original work is properly cited. 